\title{
Mydrosomella cleia, uma espécie nova de Diphaglossinae do sul do Brasil (Hymenoptera, Colletidae) ${ }^{1}$ \\ Mydrosomella cleia, a new species of Diphaglossinae from the southern of Brazil (Hymenoptera, Colletidae $)^{1}$
}

\author{
VINALTO GRAF ${ }^{2}$ \\ DANÚNCIA URBAN ${ }^{2,3}$
}

O gênero Mydrosomella foi proposto por Michener em 1986 para Diphaglossa gaullei Vachal, 1904, caracterizado pela área malar muito curta, ausência de carena pré-episternal, sulcos prescutais curtos, sutura escutelar em uma fossa profunda, segunda célula sub-marginal menor que a terceira; as fêmeas com dois pequenos dentes basais nas mandíbulas, os machos com o processo apical do oitavo esterno largo e arredondado na ponta. As medidas que constam na descrição são dadas em milímetros.

\section{Mydrosomella cleia sp.n.}

(Figs 1-8)

DiAGNOSE - Fêmea com pilosidade preta, macho com pilosidade preta e branca, porém os tergos sem faixa apical branco-pilosa decumbente.

\section{HOLÓTIPO MACHO}

Preto, exceto a face ventral das antenas castanho-pálida do segundo flagelômero ao apical; asas tingidas com marrom; tarsômeros medianos e distais castanhos.

\footnotetext{
${ }^{1}$ Contribuição n ${ }^{\circ} 1198$ do Departamento de Zoologia, SCB, Universidade Federal do Paraná ${ }^{(2)}$ Caixa Postal 19.020 - 81531-990 Curitiba, Paraná, Brasil. ${ }^{3}$ Bolsista do CNPq.
} 
Pilosidade longa e densa na cabeça (Fig. 1), no mesosoma e coxas e fêmures anteriores; mais curta no vértice, a parte dorsal da fronte quase glabra. Pêlos do tergo basal longos e com ramificações muito curtas dispostas em ângulo agudo. Branca em quase toda a cabeça passando a castanho-enegrecida no vértice; dorso do mesosoma e metade dorsal dos mesepisternos castanho-enegrecidos, o mesoscuto com larga orla esbranquiçada; metade ventral dos mesepisternos com pêlos brancos; também desta cor nos artículos basais das pernas, até o fêmur nas anteriores e medianas, e nas posteriores em todo o lado externo; tíbias e basitarsos medianos castanho-pálidos no lado externo, demais áreas das pernas com pêlos castanho-enegrecidos; face ventral dos basitarsos com cerdas castanho-avermelhadas. Esbranquiçada nos dois primeiros tergos, nos seguintes castanho-enegrecida; quatro esternos basais com pêlos brancos, longos no primeiro, e formando franja decumbente longa nos seguintes; no quinto e sexto castanha.

Cabeça micro-reticulada, opaca; labro brilhante com rugas irregulares no disco e liso nos flancos; clípeo com pontos grossos, separados por um a dois diâmetros de ponto, ausentes na margem apical, com depressão alongada no meio e, nos lados o tegumento brilhante; ramo horizontal da sutura epistomal deprimido; área supraclipeal elevada em direção à carena frontal, com pontos mais finos do que os do clípeo; carena frontal quase até o ocelo mediano; na fronte, ventralmente aos ocelos laterais, duas protuberâncias largas, estreitando para o vértice; paroculares superiores quase glabras, sem pontuação diferenciada, levemente côncavas; do ocelo lateral quase até o olho uma pequena elevação quase reta; margem interna dos olhos fracamente emarginada próximo ao vértice. Mesoscuto microreticulado, os pontos menores que os do clípeo; escutelo com a pontuação mais densa que a do mesoscuto, menos na área basal; nos tergos como no mesoscuto, porém os pontos mais esparsos e mais finos; basitarsos anteriores com uma carena fina ao longo do comprimento, ausente na fêmea; asas anteriores com a terceira célula submarginal pouco maior que a segunda (Fig.3). Sétimo tergo sem placa pigidial, com protuberância longitudinal fraca e glabra.

Sétimo esterno com os lobos laterais e medianos angulosos, os laterais mais curtos, com lâmina translúcida estriada e bissinuosa unindo externamente os lobos (Fig.4); processo apical do oitavo esterno largo e arredondado distalmente; genitália com os gonóstilos arqueados para o meio e com pêlos longos densamente ramificados, no lado externo os pêlos tão longos como a largura do gonóstilo (Figs 6 e 8 ) e na face mesal com 

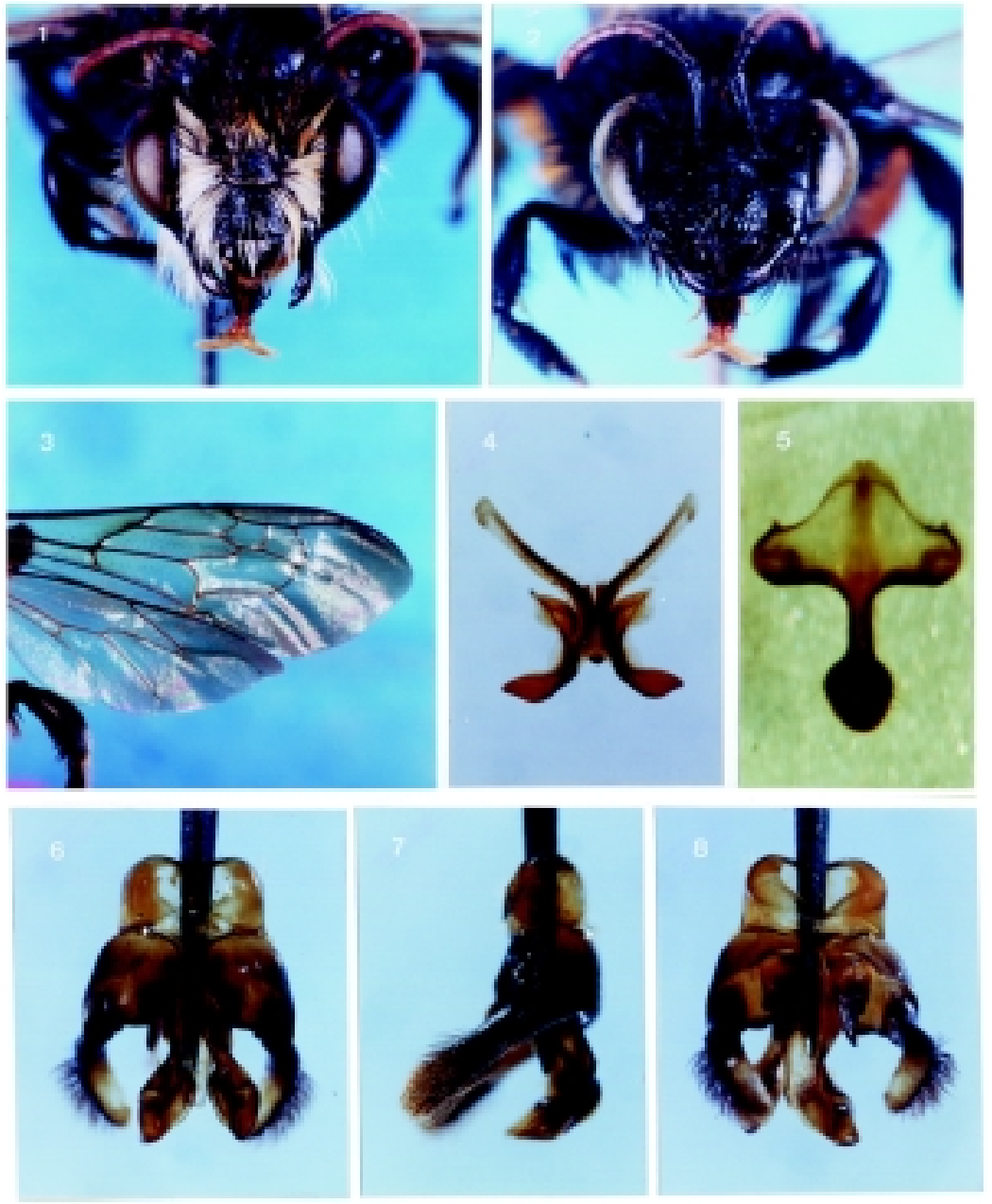

Figs 1-8. Mydrosomella cleia sp.n. 1, cabeça do macho; 2, cabeça da fêmea; 3 a 8, macho; 3 , asas; 4 , sétimo esterno; 5 , oitavo esterno; 6 a 8 , genitália, 6 , vista dorsal; 7 , perfil; 8 , vista ventral. 
pelinhos esparsos. Valvas capitadas, mais largas que os gonóstilos (Fig. 6); volselas com o ápice anguloso (Fig.8). Quando vistos de perfil, os gonocoxitos e gonóstilos dispostos em ângulo obtuso (Fig.7).

Comprimento 13,50; largura da cabeça 3,96; comprimento da asa anterior 8,75 ; distância interorbital superior igual à inferior 2,12; comprimento mínimo da área malar pouco menor que um terço da largura da base da mandíbula 0,14: 0,48; distância interalveolar maior que a alveolocular 0,64: 0,46; distância interocelar menor que o dobro do diâmetro do ocelo mediano 0,56: 0,30; flagelômero basal cônico, com 0,48 de comprimento, e 0,20 de largura na base e 0,30 no ápice; segundo e terceiro flagelômeros, respectivamente 0,30 e 0,36 de comprimento.

\section{ALÓTIPO}

Todo o tegumento preto, pilosidade inteiramente castanho-enegrecida, sem pêlos brancos (fig. 2); lados do propódeo com pêlos esparsos.

Mandíbulas com três dentes, os dois basais muito reduzidos (Fig. 2).

Comprimento 13,50; largura da cabeça 4,16; comprimento da asa anterior 9,50; distância interorbital superior 2,24 e a inferior 2,48; comprimento mínimo da área malar menor que um terço da largura da mandíbula na base $0,16: 0,56$.

HOLÓTIPO MACHO — BRASIL, Rio Grande do Sul, Osório, 20.VII.1992, I. Alves dos Santos leg. Alótipo, três parátipos machos e uma fêmea com os mesmos dados na etiqueta; um parátipo macho da mesma localidade coletado em 16.X.1992. Depositados na Coleção J. S. Moure, Departamento de Zoologia da Universidade Federal do Paraná.

Etimologia - Nome aposto, em homenagem a Cléia Maria Bento Graf.

\section{COMENTÁRIOS}

Mydrosomella gaullei, a espécie-tipo do gênero é reconhecida à primeira vista pelas faixas apicais branco-pilosas dos tergos, estreitas e densas. Os machos de M. gaullei têm as valvas um pouco mais estreitas que os gonóstilos, estes com pilosidade curta, e as volselas com o ápice arredondado; gonóstilo e gonocoxito, de perfil, com o contorno dorsal suavemente arredondado; o sétimo esterno com as placas medianas e laterais capitado-truncadas. 


\section{Mydrosomella gaullei (Vachal, 1904)}

Diphaglossa ? gaullei Vachal, 1904. Rev. d'Ent. 23: 23.

Mydrosomella gaullei; Michener, 1986. Univ. Kansas Sci. Bull. 53 (4): 196.

Anteriormente conhecida somente da ARGENTINA, Tucumán e Buenos Aires. Foram examinados macho e fêmeas do BRASIL, Rio Grande do Sul, coletados em Caçapava do Sul, Guaritas [morros-testemunho de conglomerado câmbrio-ordoviciano] por C. Schlindwein; e uma fêmea do Paraná, Curitiba, coletada por S. Laroca. Neste último exemplar a pilosidade da face ventral do mesosoma é inteiramente branca.

\section{RESUMO}

Neste trabalho é descrita Mydrosomella cleia sp.n., de Osório, Rio Grande do Sul, Brasil, segunda espécie de Mydrosomella Michener, 1986, Diphaglossinae.

Palavras chave: Mydrosomella, Colletidae, Hymenoptera, Taxonomia

\section{SUMMARY}

Mydrosomella cleia sp.n., a new Diphaglossinae from Osorio, Rio Grande do Sul, Brazil is described, is the second species of Mydrosomella, a genus proposed by Michener in 1986.

KeY words: Mydrosomella, Colletidae, Hymenoptera, Taxonomy.

\section{RÉSUMÉ}

Une nouvelle espèce d'abeille, Mydrosomella cleia, sp.n. de l'Osorio, Rio Grande do Sul, Brésil est décrit; c'est la seconde espèce de Mydrosomella, proposé pour MicheNER, 1986.

Mots clés: Mydrosomella, Colletidae, Hymenoptera, TaXonomie.

\section{BIBLIOGRAFIA}

MICHENER, C. D. 1986. A Review of the Tribes Diphaglossini and Dissoglottini (Hymenoptera, Colletidae). Univ. Kansas Sci. Bull. 53 (4):183-214.

VACHAL, J. 1904. Voyage de M. G. A. Baer au Tucuman (Argentina). Rev. d'Ent. 23: 9-26.

Recebido em 12.02.2001 